\title{
Design and Analysis of Jig and Welding Fixture for Car Panel to Shift the Locate Pin
}

\author{
Diksha R. Bahadure ${ }^{1}$, Dr. Subhash N. Waghmare ${ }^{2}$ \\ ${ }^{I}$ M.Tech. a student in Mechanical Engineering Design, Priyadarshini College of Engineering, Nagpur, India, 440022 \\ ${ }^{2}$ Assistant Professor in Mechanical Engineering Department, Priyadarshini College of Engineering,Nagpur, India, 440022
}

DOI: 10.46335/IJIES.2020.5.10.1

\begin{abstract}
The fixture is a collection of working holdings that holds, supports, and locates the workpiece. Depending on their application, the fixture is needed in different industries. The locating pin is used to restrict the panel's degree of freedom. The panel will affect the loading and unloading of the panel due to a fixed position pin, so we have to configure the shift tool to change the positioning pin during loading and unloading of the panel. In this project we will create a CAD model with a jig and welding fixture. The change unit or the position unit will be designed as compact as possible, depending on the need for the jig and the welding fixture. This project is designed to move the positioning pin between the locating pin and the panel to avoid interference during loading and unloading.
\end{abstract}

Keywords- Locating pin, panel, CAD model, welding fixture, jig

\section{I- INTRODUCTION}

$\mathbf{T}$ he jigs and fixtures are an economical way to massproduce a part. Thus jigs and fixtures are used and are one of the most critical installations of the mass production system. These are special work holding and tool guiding device. The output quality of a process primarily determined by the quality of the jigs and fittings used for this purpose. What makes a fixture special is that everyone is designed to match a particular part or shape. A fixture has the main function of locating and retaining a work piece during service. In addition to locating and supporting the work piece, a jig differs from a fixture in the sense that it directs the tool to its correct location or movement during operation. Fixture required
Specialization to accurately hold the work-piece during the welding operation. The Fixture designed hold job and rotate the job at required Speed. The reduced cycle time and operator labor while increasing functionality [1],[2], [3].

Depending on their application, the fixture is needed in different industries. Due to some drawbacks the configuration of a new fixture is changed over the current fixture. The part fixture is installed manually so loading and unloading of the material take more cycle time [4] , [5], [6], [7]. .

Work-holding methods have also changed considerably; the core principles of clamping and position are still identical. Mass production methods require a simple and easy way to put work on them for various operations. To address this issue we designed the welding fixture with enhanced mobility [8], [9], [10], [11].

In general, clamping is necessary to hold the job in the jig. Much as in the automotive market, jigs may also be concept guides or templates. Special cramping jigs to ensure that the panel is placed in the right position. The fixture is a strong and rigid mechanical device that attaches to a machine and allows the stock to slide while holding firmly, allowing for simple, easy and reliable accuracy of position, support, and clamping. A fixture is a device for locating, holding, and supporting a workpiece during a manufacturing operation. This consists of locators, clamps, supports, and fixture body [12], [13], [14], [15].

The unit's contents describe jigs and fixtures as a work piece clamping device and guiding device for the 
machine. The use of jigs and fittings directly impacts the output level of the operation. It increases work efficiency by eliminating the manufacture of low-quality goods and reducing product cycle times. Jigs and fixtures design always depends on the type of operation and the machine tool to be used for that operation. Using jig and fixture means placing the work piece in the appropriate location on the machine tool. The purpose of the position is to decide the points on the work where all the movements should be restricted so that the work can be completed without any problems [16], [17], [18], [19]. For this reason, other position principles are followed, such as 32-1 position theory, flat locator, cylindrical and conical locator, and jack pin locator. The key aim of the position theory is to curb the rigidity of the clamping. At the same time all of this leaves the production area open and ready for production. The unit also defines different types of clamping devices and the characteristics of a successful clamping system along with the attachments, jigs are used to direct the movement of the tool during service. They are made of steel that is hardy, wear-resistant, and corrosion-resistant. It also defines the widely used fixtures in the room [20], [21], [22], [23].

\section{II- METHOLOGY}

\section{$\underline{\text { Design Selection }}$}

Design selection is the process of selecting the concept that has been evaluated according to the requirement and the appropriate criteria. When comparing the relative strengths and limitations of the model, choose the best definition to be used for further analysis. Generally speaking, idea selection is the method of narrowing up the alternative definition considered [24], [25], [26], [27]. The screening form was chosen for the final design for the jig. This approach will help designers determine which concept is best.

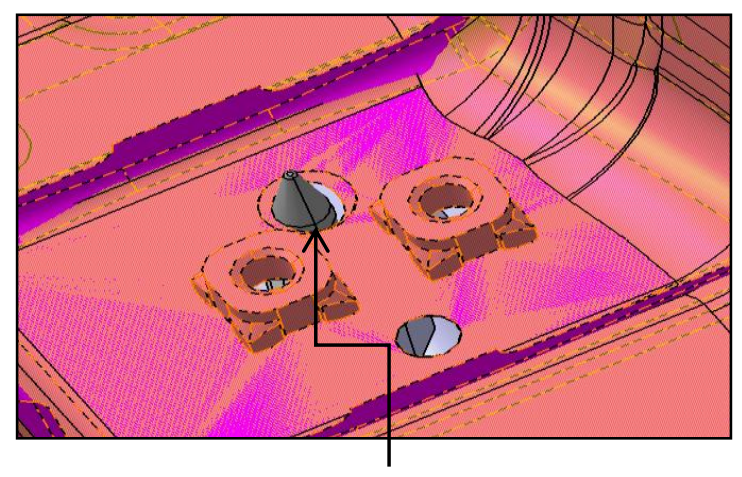

Fig. 1- Location of pin damaging panel (before modifications)

\section{Final Concept}

The final design of the semi-auto insertion jig is much better than the second design, which for this design is the assembly component, which is also simple.

\section{Basic Design Principle for Jig and Fixture}

The basic concept when designing the jig and the fixture is to help, locate, clamp, and keep the job. This concept originates from the final design of semi-auto insertion [28], [29]. The support of the part should be rigid. From this semi-auto insertion jig, make sure that the supporting design is robust enough to ensure accuracy when inserting the e-ring into the main lever portion. The fool proofing tool used for these parts is pins which clearly can position parts correctly and prevent parts from entering this jig incorrectly. Using screw clamps, this semi-auto inserter jig [30], [31]. The torque is used by the base screw clamp to hold a part in places by direct pressure on another part. The retaining power for this jig uses the screws and nuts. The bolts and nuts are simple to use and can be mounted from any component [32], [33].

\section{Design for safety}

The design of the product is safe and easy to use when designing jig and fixtures. Sharp corners should be avoided on the jig or fixture body. When designing the semi-auto insertion jig in this project, each design component uses chamfers in each corner to ensure that there is no sharp corner that can damage the operator when using the jig Bolt and groove should be inside the body and should not protrude the surface [34], [35]. The surface of this semi-auto insertion is well built as something bold is placed inside the jig which makes the work surface clear and can prevent injury and obstacles while doing the job.

\section{III- DESIGN}

\section{Force Calculation and Analysis of Clamp-}

\section{CLAMPING FORCE CALCULATION (BEFORE MODIFICATION)}

$$
\frac{F 1}{A}=\frac{F 2}{B}
$$

Where $\mathrm{F} 1=$ Clamping force

F2= Cylinder force 
International Journal of Innovations in Engineering and Science, Vol 5, No.10, 2020

\section{www.ijies.net}

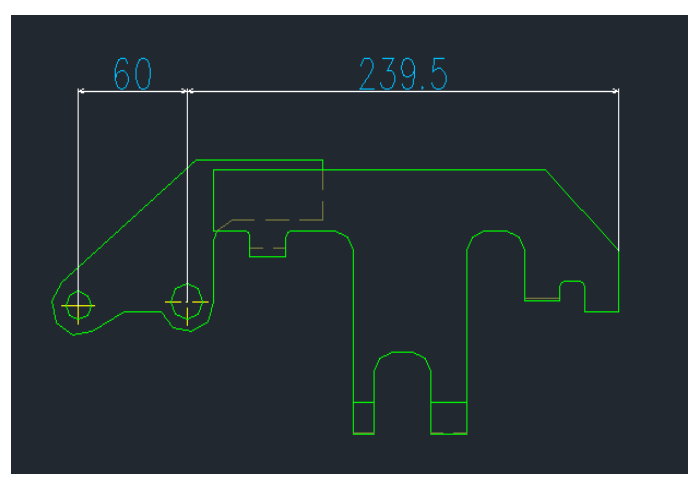

Fig. 2: Clamp dimensions of $A$ and $B$

Given,

The bore diameter of cylinder $=\Phi 50$

$\mathrm{F} 2=$ Cylinder force $=78 \mathrm{kgf}$

$$
\begin{gathered}
A=60 \mathrm{~mm} \\
B=239.5 \mathrm{~mm}
\end{gathered}
$$

Therefore,

$$
\begin{gathered}
F 1=78 * \frac{60}{239.5} \\
F 1=19.54 k g f \\
F 1=19.54 * 9.81 \\
F 1=192 \mathrm{~N}
\end{gathered}
$$

The clamping force is $192 \mathrm{~N}$

\section{CLAMPING FORCE CALCULATION (AFTER MODIFICATION)}

$$
\frac{F 1}{A}=\frac{F 2}{B}
$$

Where $\mathrm{F} 1=$ Clamping force

F2= Cylinder force

$$
F 1=F 2 * \frac{A}{B}
$$

Given,

Bore diameter of cylinder $=\Phi 63$

$$
\begin{gathered}
\mathrm{F} 2=\text { Cylinder force }=124 \mathrm{kgf} \\
\qquad \mathrm{A}=60 \mathrm{~mm} \\
\mathrm{~B}=239.5 \mathrm{~mm}
\end{gathered}
$$

Therefore,

$$
\begin{aligned}
& F 1=124 * \frac{60}{239.5} \\
& F 1=31.06 \mathrm{kgf} \\
& F 1=31.06 * 9.81 \\
& F 1=305 \mathrm{~N}
\end{aligned}
$$

The clamping force is $305 \mathrm{~N}$

Table 1-According to Japanese Industrial Standards (JIS) bore diameter and force of cylinder is given below

\begin{tabular}{|c|c|c|}
\hline Sr.no & $\begin{array}{c}\text { The bore diameter } \\
\text { of the cylinder }\end{array}$ & Cylinder force \\
\hline 1 & $\Phi 40$ & $78 \mathrm{kgf}$ \\
\hline 2 & $\Phi 50$ & $78 \mathrm{kgf}$ \\
\hline 3 & $\Phi 63$ & $124 \mathrm{kgf}$ \\
\hline 4 & $\Phi 80$ & $201 \mathrm{kgf}$ \\
\hline
\end{tabular}

Table 2- Mechanical Properties of Steel (SS400)

\begin{tabular}{|c|c|c|c|}
\hline Sr.no & Stress & Safety factor & $\begin{array}{c}\text { Allowable } \\
\text { stress (MPa) }\end{array}$ \\
\hline 1 & Tensile & 1.67 & 140 \\
\hline 2 & Compression & 1.67 & 140 \\
\hline 3 & Bending & 3.0 & 80 \\
\hline 4 & Shear & 1.67 & 140 \\
\hline
\end{tabular}

Table 3-Maximum allowable deflection ( $\mathrm{mm}$ )

\begin{tabular}{|c|c|c|}
\hline Sr.no & Parts & $\begin{array}{c}\text { Allowable deflection } \\
(\mathrm{mm})\end{array}$ \\
\hline 1 & Stool & 0.5199 \\
\hline 2 & Bracket & 0.306 \\
\hline 3 & Stopper & 0.391 \\
\hline 4 & Clamp & 0.203 \\
\hline
\end{tabular}

Table 4- Thermal Properties of Steel (SS400)

\begin{tabular}{|c|c|c|c|}
\hline Sr.no & $\begin{array}{c}\text { Temperature } \\
\left({ }^{0} \mathrm{C}\right)\end{array}$ & $\begin{array}{c}\text { Young } \\
\text { Modulus(GPa) }\end{array}$ & $\begin{array}{c}\text { Poisson's } \\
\text { ratio }\end{array}$ \\
\hline 1 & 50 & 209.05 & 0.3 \\
\hline 2 & 100 & 205.74 & 0.3 \\
\hline 3 & 200 & 198.90 & 0.3 \\
\hline 4 & 300 & 192.14 & 0.3 \\
\hline 5 & 400 & 183.65 & 0.3 \\
\hline 6 & 500 & 174.52 & 0.3 \\
\hline
\end{tabular}

Table 5- According to Japanese Industrial Standards (JIS) flat steel sizes are given below 
International Journal of Innovations in Engineering and Science, Vol 5, No.10, 2020

$w w w . i j i e s . n e t$

\begin{tabular}{|c|c|c|c|c|}
\hline \multirow[t]{2}{*}{ Sr.no } & \multicolumn{2}{|c|}{ Sectional Dimension } & \multirow{2}{*}{$\begin{array}{l}\text { Break } \\
\text { area } \\
\left(\mathrm{cm}^{2}\right)\end{array}$} & \multirow{2}{*}{$\begin{array}{c}\text { Unit } \\
\text { weight } \\
(\mathrm{Kg} / \mathrm{m})\end{array}$} \\
\hline & $\begin{array}{c}\text { Thickness } \\
(\mathrm{mm})\end{array}$ & Width(mm) & & \\
\hline \multirow[t]{12}{*}{1} & & 100 & 12 & 9.42 \\
\hline & 12 & 125 & 15 & 11.8 \\
\hline & & 150 & 18 & 14.1 \\
\hline & & 180 & 21.6 & 17 \\
\hline & & 200 & 24 & 18.8 \\
\hline & & 230 & 27.6 & 21.7 \\
\hline & & 250 & 30 & 23.6 \\
\hline & & 280 & 33.6 & 26.4 \\
\hline & & 300 & 36 & 28.3 \\
\hline & & 32 & 5.12 & 4.02 \\
\hline & & 38 & 6.08 & 4.77 \\
\hline & & 44 & 7.04 & 5.53 \\
\hline \multirow[t]{13}{*}{2} & 16 & 50 & 8 & 6.28 \\
\hline & & 65 & 10.4 & 6.16 \\
\hline & & 75 & 12 & 8.16 \\
\hline & & 90 & 14.4 & 9.42 \\
\hline & & 100 & 16 & 11.3 \\
\hline & & 125 & 20 & 12.6 \\
\hline & & 150 & 24 & 15.7 \\
\hline & & 180 & 28.8 & 18.8 \\
\hline & & 200 & 32 & 22.6 \\
\hline & & 230 & 36.8 & 25.1 \\
\hline & & 250 & 40 & 28.9 \\
\hline & & 280 & 44.8 & 31.4 \\
\hline & & 300 & 48 & 35.2 \\
\hline
\end{tabular}

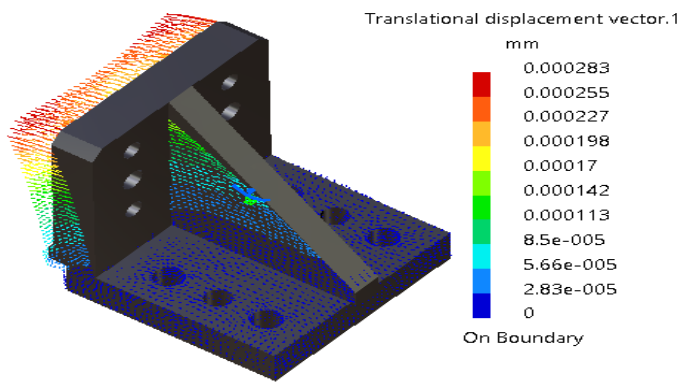

Fig. 4: Model (Stool) showing deflection in SS400

The maximum deflection develops in the above part is $0.000283 \mathrm{~mm}$, which is less than the maximum allowable deflection as shown in table 3. Therefore, the design is

The finite element analysis of the parts of the jig is given below:

To shift the locating pin, the shift cylinder arrangement is designed because of that stresses are developed in the following parts.

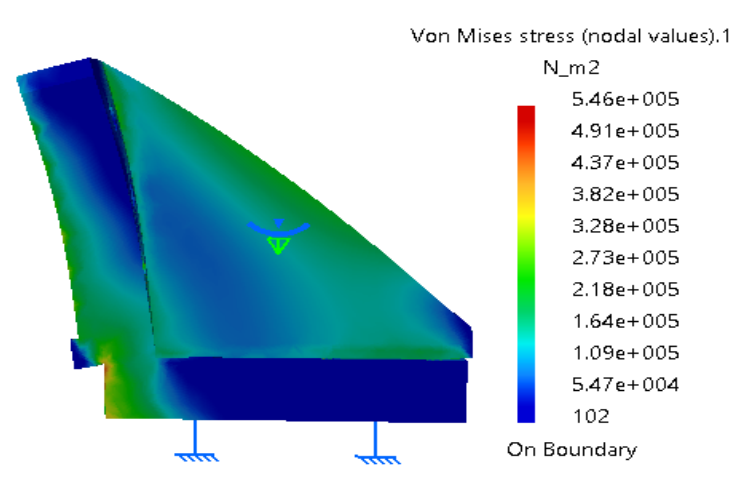

Fig. 3: Model showing stresses in SS400

The maximum stress develops in the above part is $5.46 \mathrm{e}+005$, which is $54.6 \mathrm{MPa}$. This is less than maximum allowable stresses as shown in table 2 . Therefore, the design is safe. safe.

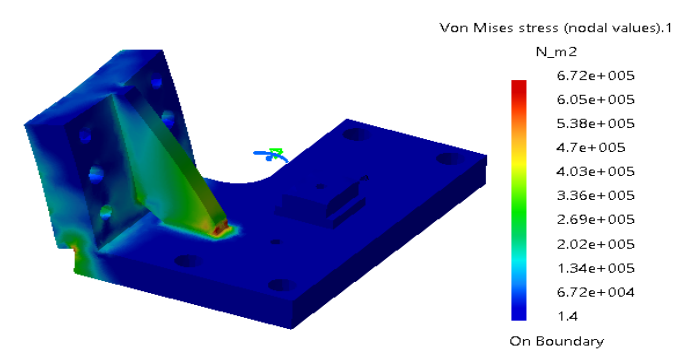

Fig. 5: Model showing stresses in SS400

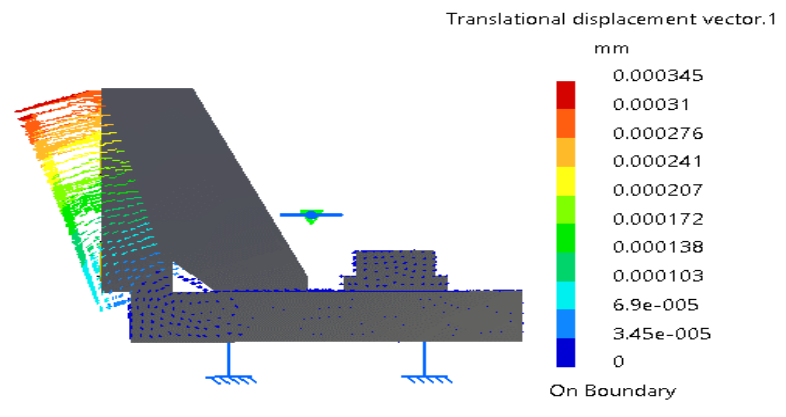

Fig. 6: Model (Bracket) showing deflection in SS400

The maximum deflection develops in the above part is $0.000345 \mathrm{~mm}$, which is less than the maximum allowable deflection as shown in table 3 . Therefore, the design is safe. 


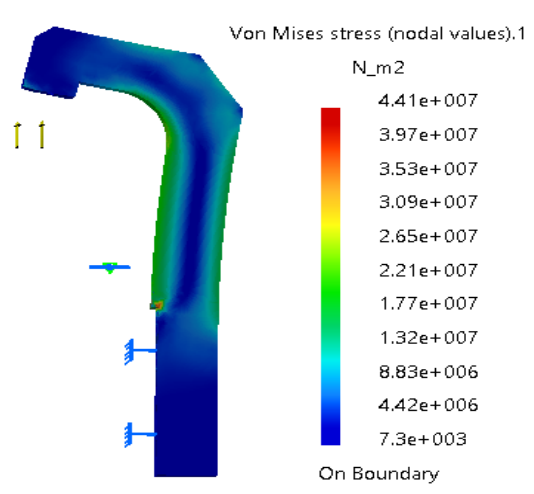

Fig. 7: Model (Stopper) showing stresses in SS400

The maximum stress develops in the above part is 5.46e+007, which is $54.6 \mathrm{MPa}$. This is less than maximum allowable stresses as shown in table 2 . Therefore, the design is safe.

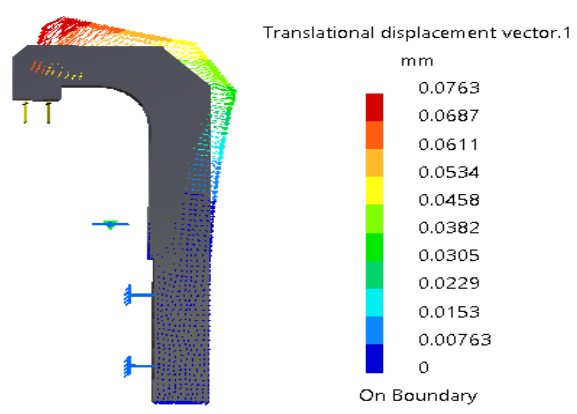

Fig. 8: Model (Stopper) showing deflection in SS400

The maximum deflection develops in the above part is $0.0763 \mathrm{~mm}$, which is less than the maximum allowable deflection as shown in table 3 . Therefore, the design is safe.

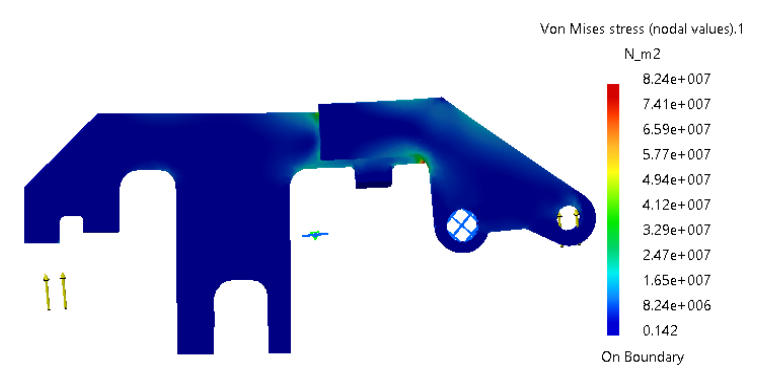

Fig. 9: Model (Clamp) showing stresses in SS400

The maximum stress develops in the above part is $8.24 \mathrm{e}+007$, which is $82.4 \mathrm{MPa}$. This is less than maximum allowable stresses as shown in table 2 . Therefore, the design is safe.

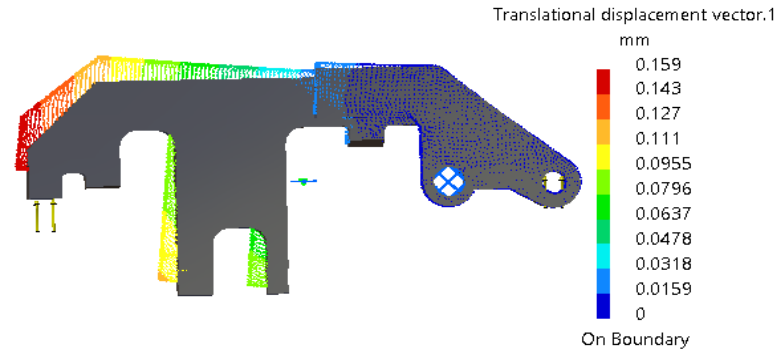

Fig. 10: Model (Clamp) showing deflection in SS400

The maximum deflection develops in the above part is $0.159 \mathrm{~mm}$, which is less than the maximum allowable deflection as shown in table 3 . Therefore, the design is safe.

The engineering design process is one of the steps required for product creation. Phase in the design of a jig and fixture is to find the right combination of design characteristics at a fair cost by assessing its functional requirements. At this point, the tool design process will clearly state the problem that needs to be solved and accomplished. The design process also included research involving the product, such as the clamping location, load distribution, selection of materials, and more research and design details. This method will also clarify how to build the semi-auto e-ring insertion jig and how to carry out the study. The software CATIA CAD is used for the design. These values are very necessary to decide if the design of the component is acceptable and complies with the requirement.

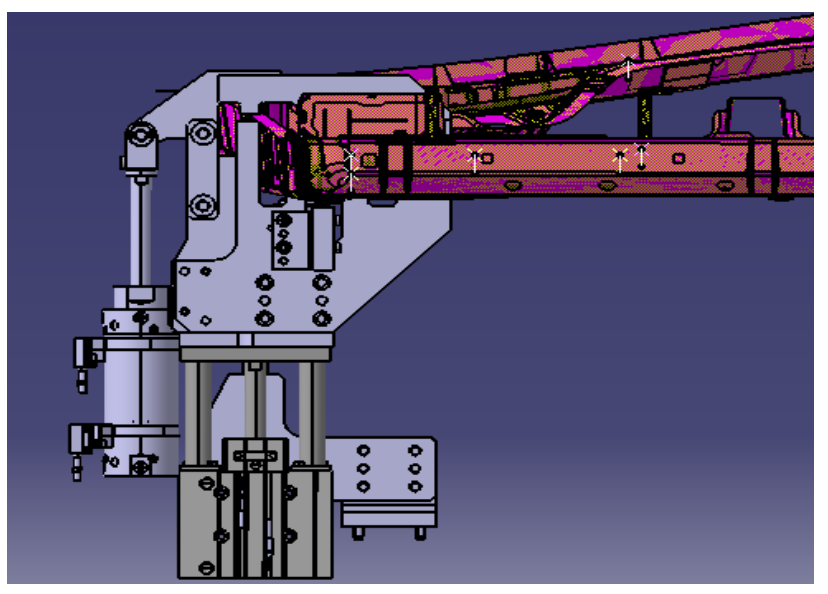

Fig. 11: Jig with Shift cylinder arrangement

The shift unit is shifted $70 \mathrm{~mm}$ below as the shift cylinder is of $75 \mathrm{~mm}$ stroke length. $5 \mathrm{~mm}$ clearance is maintained.

By using these flat bar sizes the parts of the jig and welding fixture has designed. All parts of the jig are shown in figure 11. 


\section{International Journal of Innovations in Engineering and Science, Vol 5, No.10, 2020} www.ijies.net

\section{IV- CONCLUSION}

In this research work, the shift unit in the jig is made as compact as possible according to the necessity of the jig and the welding fixture. This project has planned to shift the locating pin to prevent interference during the landing and takeoff of the panel. To make this kind of arrangement some parts of the jig have to modify. By using Japanese Industrial Standards (JIS) parts get modified in CATIA. By using the same, parts get drafted in Auto CAD; with the modifications in design the objective is achieved.

\section{REFERENCES}

[1] Prit Shah, Hetal Agrawal, S P Joshi, Udayan Patel, "Design and Manufacturing of Modular Welding Fixture", National Conference on Recent Trends in Engineering \& Technology, 2011

[2] S.N.Shinde, Siddharth Kshirsagar, Aniruddha Patil, Tejas Parge, Ritesh Lomte, "Design of Welding Fixtures and Positioners", International Journal of Engineering Research and General Science, Volume 2, Issue 5, ISSN 2091-2730, August-September, 2014

[3] Bing Li. Hui Tang. Xiaoping Yang. Hao Wang, "Quality design of fixture planning for sheet metal assembly", International Journal of Manufacturing Technology, 2007

[4] Waghmare S.N., Sakhale C.N., Tembhurkar C.K., Shelare S.D. (2020) Assessment of Average Resistive Torque for Human-Powered Stirrup Making Process. In: Iyer B., Deshpande P., Sharma S., Shiurkar U. (eds) Computing in Engineering and Technology. Advances in Intelligent Systems and Computing, vol 1025. Springer, Singapore. https://doi.org/10.1007/978-981-32-9515-5_79

[5] Biswajit Parida, Shiv Dayal Vishwakarma and Sukhomay Pal, "Design and development of fixture and force measuring system for friction stir welding process using strain gauges", Springer Publication, Journal of Mechanical Science and Technology, 2015

[6] Naveen A M, V A Girisha, Pruthvi HM, "Design and Analysis of Welding Fixture for Motor Case Assembly", International Journal of Mechanical and Production Engineering, ISSN: 2320-2092, Volume- 2, Issue-8, August 2014

[7] Kalpesh Khetani, Jafar Shah, Vishal Patel, "Design and Thermal Stress Analysis of Welding Fixture of a Brake Pedal", International Journal on Recent Technologies in Mechanical and Electrical Engineering, ISSN: 23497947 Volume: 2 Issue: 5, pp 029-032, May 2015.

[8] Waghmare S.N., Shelare S.D., Tembhurkar C.K., Jawalekar S.B. (2021) Development of a Model for the
Number of Bends During Stirrup Making Process. In: Prakash C., Krolczyk G., Singh S., Pramanik A. (eds) Advances in Metrology and Measurement of Engineering Surfaces. Lecture Notes in Mechanical Engineering. Springer, Singapore. https://doi.org/10.1007/978-98115-5151-2_7

[9] Omkar Joshi, Dr. Arunkumar, "Design and Analysis of Welding Fixture For Orbital Welding Machine", International Journal of Production Management and Engineering, Volume III Issue IV, October-December 2015

[10] Shelare S.D., Kumar R., Khope P.B. (2021) Formulation of a Mathematical Model for Quantity of Deshelled Nut in Charoli Nut Deshelling Machine. In: Prakash C., Krolczyk G., Singh S., Pramanik A. (eds) Advances in Metrology and Measurement of Engineering Surfaces. Lecture Notes in Mechanical Engineering. Springer, Singapore. https://doi.org/10.1007/978-981-15-51512_9

[11] Yogesh Ingale, Kuldip Rade, Nitin Bhalerao, Dr. Kailas Nath Suta, "Design and Analysis of Welding Fixture for Inlet Header of Shell and Tube Heat Exchanger", International Journal of Engineering Research, 2015

[12] Waghmare S., Shelare S., Sirsat P., Pathare N, Awatade S. (2020) Development Of An Innovative Multi-Operational Furnace. International Journal of Scientific \& Technology Research Volume 9, Issue 04, April 2020. Pp 885-889.

[13] Jigar D Suthar, K.M Patel, Sanjay G Luhana "Design and analysis of fixture for welding an exhaust impeller", International Journal of Engineering Science Direct and Technology, Vol. 51, pp 514-519, 2013

[14] Chetan D. Borse, Prasad V. These, Ravi P. Vishwakarma, Jainendrakumar S. Yadav, "Design and Analysis of Fixture for a Stone Crusher Body" On International Journal of Research in Engineering and Technology, ISSN: 2319-1163, ISSN: 2321-7308, Volume: 04 Issue: 06, June 2015.

[15] Jawalekar, S. B., and S. D. Shelare. 2020. Development and performance analysis of low cost combined harvester for rabicrops. Agricultural Engineering International:CIGR Journal, 22 (1):197-201.

[16] S. D. Shelare, P.S. Thakare and Dr. C. C. Handa, "Computer Aided Modelling and Position Analysis of Crank and Slotted Lever Mechanism”, International Journal of Mechanical Engineering and Production engineering Research and Development, Volume 2, No 2, June 2012, PP 47-52.

[17] Vaishak Bhandari M, Sudeep N S, Naveenakrishna $P$ V, "Design and Analysis of Robot Full Welding Fixture for 
Front Chassis of Wheel Loader" NCAMES, ISSN: 22315381, 2016

[18] Mali, P., C.Sakhale, and S. Shelare.2015. A literature review on design and development of maize thresher. International Journal of New Technologies in Science and Engineering, 3(9):9-14

[19] A. M. Mhaske, R. M. Metkar, S. D. Hiwase "Design and Analysis of Welding Fixture for Tacking and Welding of Inner Boom of Loadall Handler", International Journal of Research in Mechanical Engineering and Technology, ISSN: 2249-5762, Vol. 5, Issue 2, May-Oct 2015

[20] Kumbhare H., Shelare S.. (2020) Innovative Advancement in Drone Technology for Water Sample Collections -A Review. International Journal of Scientific \& Technology Research Volume 9, Issue 03, March 2020. Pp 72667269.

[21] H. Asada and A. By, "Kinematic analysis of work part fixturing for flexible assembly with automatically reconfigurable fixtures", IEEE Journal of Robotics and Automation, 2, pp 86-93, 1984.

[22] Mowade S., Waghmare S., Shelare S., Tembhurkar C. (2020) Mathematical Model for Convective Heat Transfer Coefficient During Solar Drying Process of Green Herbs. In: Iyer B., Deshpande P., Sharma S., Shiurkar U. (eds) Computing in Engineering and Technology. Advances in Intelligent Systems and Computing, vol 1025. Springer, Singapore https://doi.org/10.1007/978-981-32-9515-5_81

[23] K. Wright and C. C. Hayes, "Automated planning in the machining The domain", Knowledge-Based Expert Systems for Manufacturing, ASME, PED-24, pp 221232, 1986.

[24] Mathew J.J., Sakhale C.N., Shelare S.D. (2020) Latest Trends in Sheet Metal Components and Its Processes-A Literature Review. In: Sharma H., Govindan K., Poonia R., Kumar S., El-Medany W. (eds) Advances in Computing and Intelligent Systems. Algorithms for Intelligent Systems. Springer, Singapore. https://doi.org/10.1007/978-981-15-0222-4_54

[25] Sakhale C.N., Bapat P.M. and Singh M.P., -Design Of Experimentation And Application Of Methodology of Engineering Experimentation To Investigation of Processing Torque, Energy And Time Required In Bamboo Processing Operations\|, International Journal of Bamboo and Rattan, April 2011 Vol. 9. 1\&2, Jbr 284, Pp:13-27.

[26] Waghmare S., Mungle N., Tembhurkar C., Shelare S., Sirsat P., Pathare N. (2019) Design and Analysis of Power Screw for Manhole Cover Lifter. International Journal of Recent Technology and Engineering, Volume
8, Issue 2, July 2019. Pp. 2782-2786, DOI: 10.35940/ijrte.B2628.078219

[27] Y. C. Chou, V. Chandru, and B. Barash, "A mathematical approach To automatic configuration of machining fixtures: analysis and Synthesis", Transactions ASME, Journal of Engineering for Industry, 111(4), pp 299306, 1989.

[28] Sahu P., Shelare S., Sakhale C. (2020) SMART CITIES WASTE MANAGEMENT AND DISPOSAL SYSTEM BY SMART SYSTEM: A Review. International Journal of Scientific \& Technology Research Volume 9, Issue 03, March 2020. Pp 4467-4470.

[29] Sakhale C.N., Bapat P.M., Singh M.P., ModakJ.P., "Design of a Comprehensive Bamboo processing Machine”, IFTToM:PICA-2006, 11th-14th July,2006,Vol.1, Pp.51-54.

[30] A. Y. C. Nee, K. Whybrew, and A. Senthil Kumar, Advanced Fixture Design for FMS, Springer-Verlag, 1995.

[31] Waghmare S., Sirsat P., Sakhale C., Shelare S., Awatade S. (2017) A Case Study on Improvement of Plant Layout for Effective Production. International Journal of Mechanical and Production Engineering Research and Development, Volume 7, Issue 5, Oct 2017. Pp. 155-160

[32] P H Joshi, "Jigs and Fixtures", Third Edition, 2004, (Tata McGraw Hill Publishing)

[33] Shelare SD, Handa C. Tsynthesis in Simulation and sensitivity analysis of quick return mechanism. LAP LAMBERT Academic Publishing: December (2012).

[34] Mehta G. D. and Modak J. P., "An Approach to establish vibration Response at all Bearings of a Counter shaft due to all Machine Elements on it ", 13th world congress in Mechanism \& Machine Science, Guanajuato, Mexico, 19-25 June, 2011.

[35] Mehta, Girish and Deogirkar, Sagar and Borkar, Prerna and Shelare, Sagar and Sontakke, Sonam, Estimation of Vibration Response of a Bridge Column (February 24, 2019). Proceedings of International Conference on Sustainable Computing in Science, Technology and Management (SUSCOM), Amity University Rajasthan, Jaipur - India, February 26-28, 2019, Available at SSRN: $\quad$ https://ssrn.com/abstract $=3356326$ or http://dx.doi.org/10.2139/ssrn.3356326 